\title{
9
}

Oficina Económica y Comercial de España en San Juan*

\section{MOMENTO CRUCIAL PARA PUERTO RICO Una economía desconocida integrada en el mercado estadounidense}

El objetivo de este artículo es trasladar a los lectores una visión concreta de la actual situación económica, social y política de Puerto Rico, así como dar a conocer las perspectivas con las que la isla afronta la recuperación de unas infraestructuras devastadas por el paso de los huracanes Irma y María en septiembre de 2017, lo que agravó aún más su situación financiera, pero también ha supuesto una oportunidad ante las necesidades de reconstrucción y la recepción de nuevos fondos federales.

Este artículo pretende explicar los efectos para Puerto Rico de su especial relación con EEUU. Además, dado el momento crucial para la isla, queremos dar a conocer las particularidades de Puerto Rico a las empresas españolas, las cuales podrían aprovechar nuestra proximidad dados nuestros fuertes vínculos históricos y culturales.

Palabras clave: reconstrucción, Estado Libre Asociado, deuda, EEUU, sector farmacéutico, fondos federales.

Clasificación JEL: F15, F36, F50, F55, H70, N12, O10.

\section{Introducción}

Hemos de comenzar recordando que Puerto Rico es un Estado Libre Asociado de EEUU, dicho lo cual, no es de extrañar que en España se tenga cierto desconocimiento de las implicaciones políticas y económicas que ello supone. Y con la intención de aclarar esta peculiar forma de gobierno, creemos adecuado reflejar brevemente su historia reciente.

\footnotetext{
* Este artículo ha sido elaborado por M. a Rosario Paradinas Zorrilla, Consejera Económica y Comercial de España en Puerto Rico. Técnico Comercial y Economista del Estado; y por María Eugenia Poveda González, Becaria ICEX.

Versión de diciembre de 2018.
}

Es por todos sabido que Puerto Rico formó parte del territorio español hasta 1898, cuando, tras la Guerra Hispanoamericana y el Tratado de París, pasó a ser territorio de EEUU en 1900. Bajo la Ley Foraker se estableció un gobierno militar y en 1917, bajo la Ley Jones, se otorgó la ciudadanía estadounidense a los puertorriqueños. No obstante, la primera mitad del siglo xx en Puerto Rico quedó marcada por el constante debate en torno al estatus político que debía regir en la isla. Siendo aparentemente dos las opciones: la anexión como un estado más de Estados Unidos o la independencia total de dicho país. Finalmente, se impuso una fórmula intermedia, tan novedosa como $D$ 
incierta, el «Estado Libre Asociado». Corría el año 1952.

Pero ¿qué implica formar parte de un Estado Libre Asociado (ELA)? A grandes rasgos podemos decir que los puertorriqueños, residentes en la isla, disponen de pasaporte americano, pero no votan en las elecciones presidenciales. Puerto Rico tiene un representante, elegido democráticamente, en el pleno de la Cámara de Representantes, con voz pero sin voto, denominado comisionado residente. La legislación está repartida en función a las competencias que aborde, si bien las leyes y políticas federales de EEUU rigen no solo las relaciones internacionales, migración, aduanas y seguridad nacional de Puerto Rico, sino que también regulan las comunicaciones, el mercado laboral o los sistemas monetario y bancario.

A nadie se le escapa que a día de hoy el debate político sigue girando entre las opciones del statu quo (ELA), la independencia o la anexión total a EEUU. No en vano, los dos principales partidos políticos se distinguen principalmente por dichas variantes ideológicas. Se han realizado diferentes plebiscitos que solo han servido para medir la popularidad de cada opción, pues ninguno de ellos estuvo avalado por el Gobierno federal, último órgano que ha de aprobar la medida en cuestión. En el último referéndum (2017) se impusieron los partidarios de la estadidad (anexión a EEUU), si bien el índice de participación fue extremadamente bajo (22\%). Actualmente el partido que gobierna la isla es partidario a la citada anexión.

\section{Particularidades de Puerto Rico}

\subsection{Evolución del crecimiento del PIB}

Las relaciones económicas de Puerto Rico con EEUU son fundamentales para su economía. De hecho, a Puerto Rico hay que verlo más como una economía regional dentro de la economía estadounidense que como una economía nacional.

Una de las primeras preguntas a plantear es si existe una correlación directa entre el ciclo económico de ambas regiones. Analizando la evolución del producto interior bruto (PIB), desde los años 1980, observamos que sí existe una cierta correlación entre la evolución del PIB de EEUU y Puerto Rico. La economía estadounidense tiende a liderar la evolución del PIB de la isla de Puerto Rico, si bien se observa un efecto de magnitud limitada y con cierto retraso para la economía de Puerto Rico.

Esta correlación se explica, fundamentalmente, tanto por las condiciones externas favorables como por la fuerte intervención gubernamental a nivel federal. Como ejemplo, destacar una de las medidas más exitosas, como fue el establecimiento del Código de Rentas Internas, la sección 936.

La sección 936 del Código de Rentas Internas, establecida en 1976, fue una medida del Gobierno federal de Estados Unidos para promover que las corporaciones norteamericanas pudieran utilizar Puerto Rico como fuente de inversión, al quedar eximidas de pagar contribuciones federales. La medida promovió la industria bancaria y financiera, además de las manufactureras, principalmente los sectores farmacéutico y electrónica. A pesar del debate sobre las ventajas e inconvenientes de esta sección, sí podemos afirmar que esta exención permitió el establecimiento y desarrollo de un sector industrial en Puerto Rico más intensivo en capital y con mayor contenido tecnológico.

No obstante, en los años 1990, ante la situación de déficit presupuestario de EEUU, el Gobierno estadounidense (Bill Clinton) recomendó su eliminación. Finalmente, la sección $\triangleright$ 


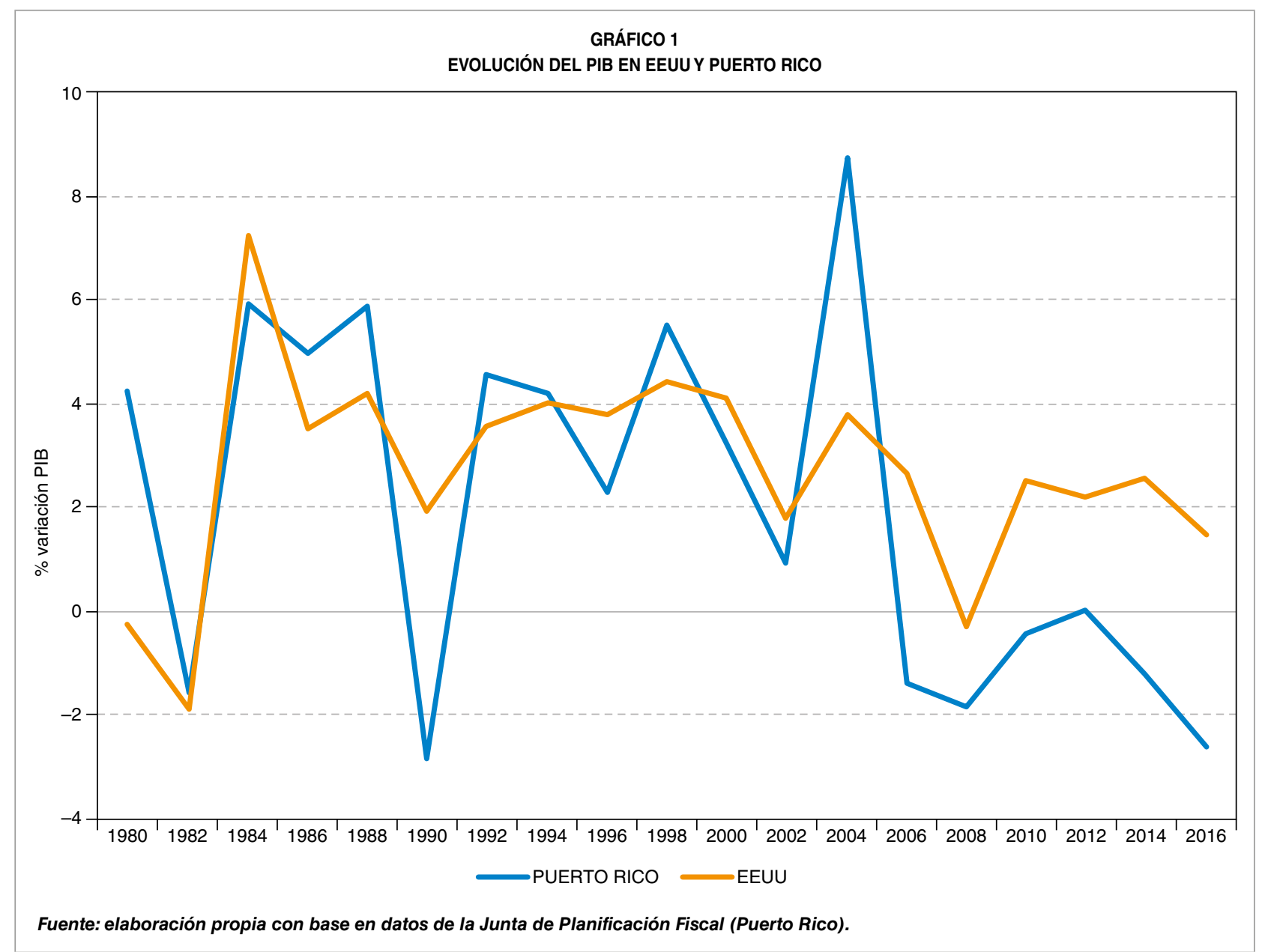

936 se derogó en 1996, estableciéndose un período de gracia de diez años para las compañías que permanecieran en Puerto Rico. El efecto fue negativo, pues, como se puede observar, desde 1997 se produjo una fuerte caída en el crecimiento de la isla, unida a una importante pérdida de empleos relacionados con la manufactura.

Finalmente, en sustitución de la 936 surgió la sección 901 del Código de Rentas Internas, y hoy, las corporaciones que se han mantenido en la isla que fueron parte de la sección 936 son clasificadas como corporaciones foráneas. Otro factor que explica la correlación entre la evolución del PIB son las exportaciones de Puerto Rico a Estados Unidos, que suponen más del $75 \%$ del total, como analizaremos posteriormente. De esta forma, tanto los intercambios comerciales como los movimientos de capital y las decisiones de las empresas estadounidenses, junto con las transferencias federales, explican un alto porcentaje de la evolución de la economía de Puerto Rico.

En definitiva, el desempeño y la evolución de la economía estadounidense son factores decisivos para la economía puertorriqueña, si bien la economía de la isla responde con cierto retraso y no se ha beneficiado de las mayores tasas de crecimiento, lo que demuestra la fragilidad del vínculo entre los ciclos.

Tal y como sugieren economistas como José Alameda, catedrático de la Universidad de Puerto Rico (UPR), en su artículo «La sensibilidad de la economía de Puerto Rico ante los $\square$ 
ciclos económicos de Estados Unidos» (1989), señala que no hay que olvidar que la economía de Puerto Rico podría estar sujeta a una mayor influencia de variables ajenas al comportamiento de la economía estadounidense. Una posible explicación sería la denominada globalización de las empresas. El crecimiento de sectores industriales como el farmacéutico, tan determinante en el PIB de la isla, depende de cadenas globales y sigue una lógica que no obedece únicamente a la economía estadounidense.

\subsection{Análisis de la brecha entre PIB y PNB}

Otro de los datos más significativos de la economía de Puerto Rico es la destacada diferencia entre el nivel del producto interior bruto $(\mathrm{PIB})$ y del producto nacional bruto (PNB).
Como se puede observar en el Gráfico 2, el PIB es siempre superior al PNB, es decir, el ingreso que se genera dentro de la isla es mayor que el propio ingreso de sus residentes. Esta diferencia se produce porque gran parte de los recursos generados son de propiedad extranjera, por lo que pertenecen a no residentes y no quedan incluidos dentro del PIB, lo que explica el proceso de desnacionalización de la economía de la isla, excesivamente dependiente de la inversión extranjera.

De la misma manera, la balanza de pagos de Puerto Rico muestra el continuo financiamiento de su déficit comercial y por cuenta corriente, a través de la entrada de capital vía inversión extranjera directa, de titularidad principalmente norteamericana. Se experimenta, por lo tanto, un mecanismo de ajuste automático de tipo regional con EEUU, su principal socio comercial. $\quad \triangleright$

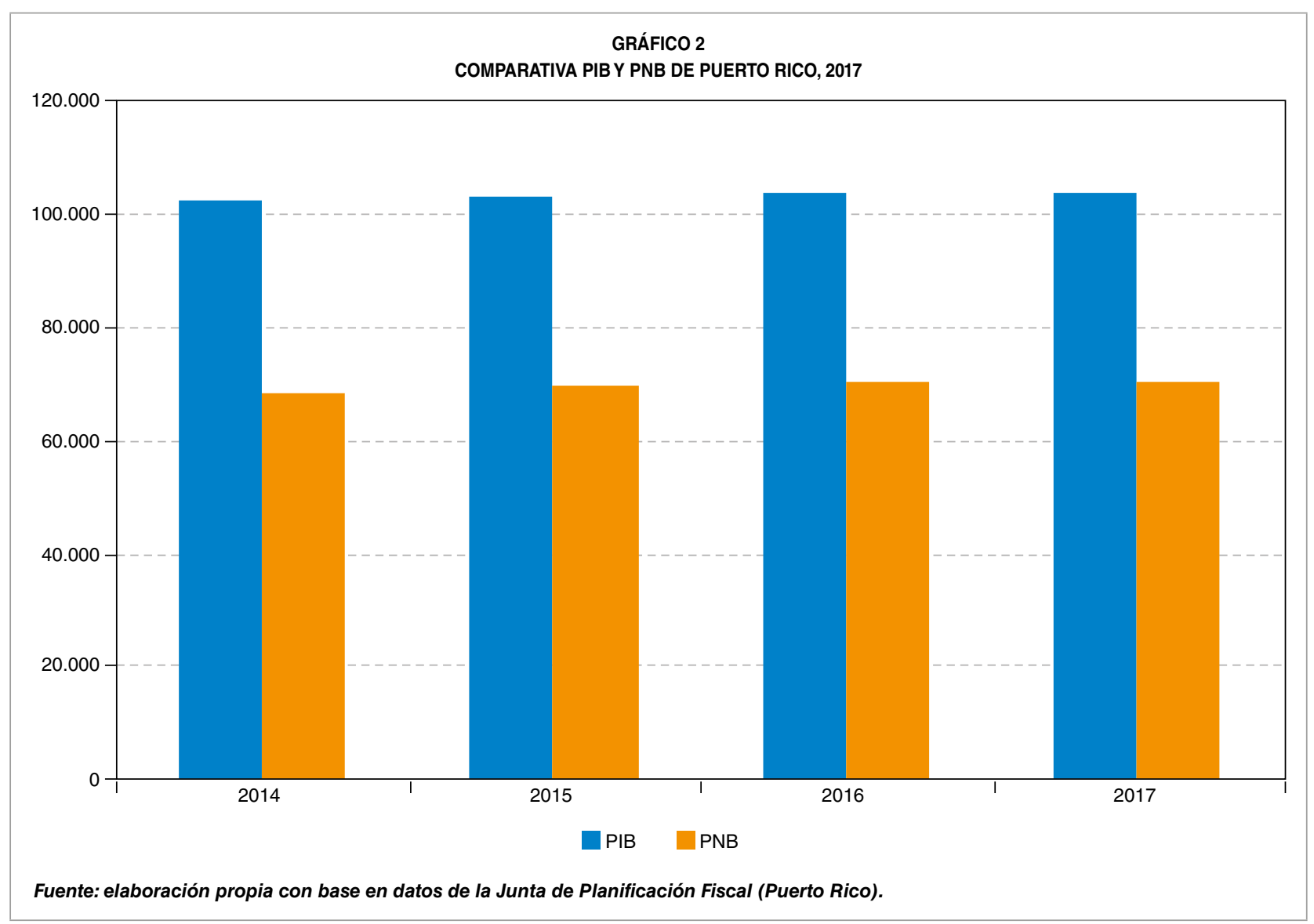


No obstante, y a pesar de esta diferencia, conviene destacar los efectos positivos de la recepción de la inversión extranjera directa en Puerto Rico, derivados de la entrada y el establecimiento de numerosas empresas extranjeras, especialmente norteamericanas. Estas han permitido el desarrollo de la economía local, una importante transferencia tecnológica, la creación de empleo y el incremento del nivel de formación gerencial, entre otros efectos directos e indirectos.

\subsection{Importancia del sector manufacturero}

El sector manufacturero en Puerto Rico representa una pieza clave en la economía. Este sector es la actividad económica que más contribuye al PIB: prácticamente representa la mitad de la producción (48\%), además de emplear a un número mayor de personas en comparación con otros sectores importantes como los bienes raíces o incluso la Administración.

Dentro del sector manufacturero, como se puede observar en el Gráfico 4, los productos

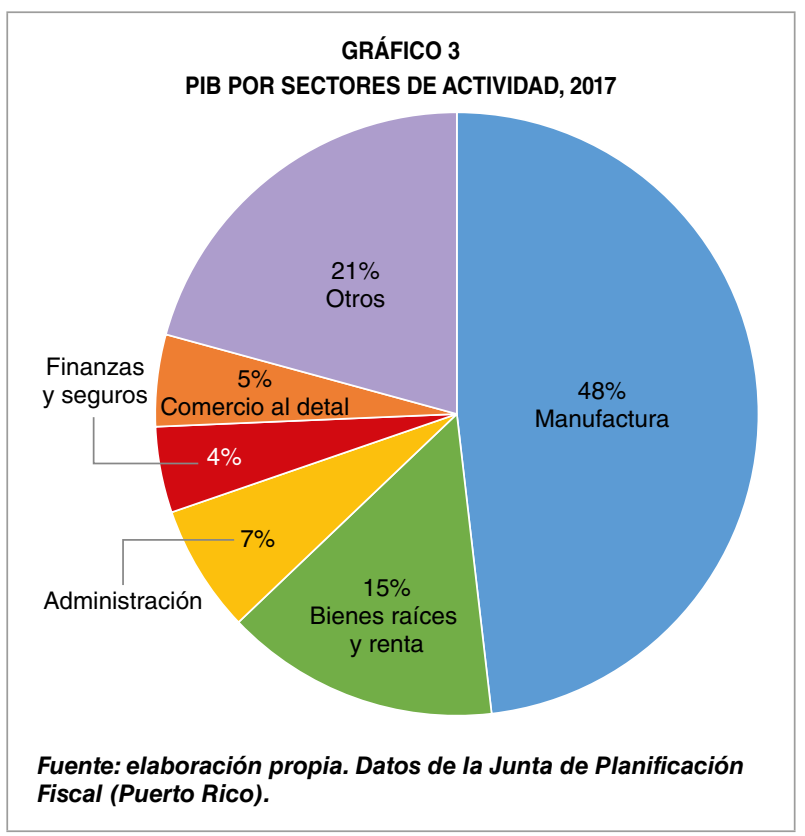

químicos (farmacéuticos y medicinas) suponen un $79 \%$ del total, lo que explica la gran importancia de la inversión del sector farmacéutico en Puerto Rico. De hecho, en la isla están establecidas 12 de las 20 mayores multinacionales del sector, con 79 plantas manufactureras aprobadas por la Food and Drug Administration (FDA), así como 13 de las 20 principales empresas fabricantes de dispositivos médicos.

A pesar de los incentivos fiscales, el sector farmacéutico aporta el 30\% del total de los impuestos que recibe el Estado, además de generar unos 18.000 empleos directos y unos 68.000 indirectos aproximadamente.

\section{Ventajas e inconvenientes de su integración en el mercado estadounidense}

Como hemos ido adelantando, Puerto Rico es una economía pequeña integrada de forma profunda en una de tamaño mucho mayor, la de EEUU. En este marco, existen simultáneamente aspectos positivos que contribuyen a $D$

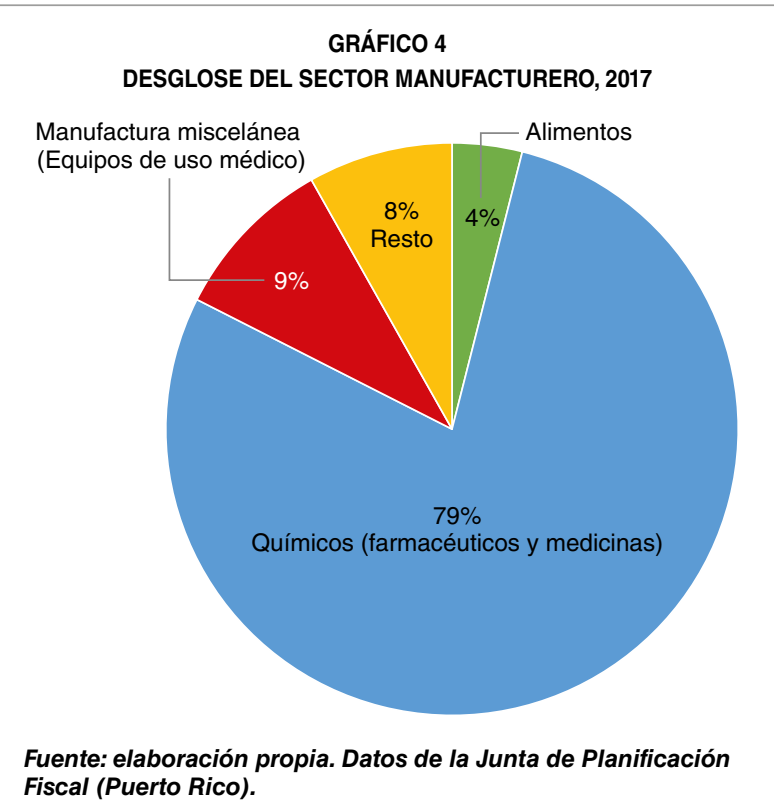


la estabilidad macroeconómica de la isla y a su desarrollo, y otros aspectos menos favorables que limitan su crecimiento.

\subsection{Ley Jones y el acceso al mercado de EEUU}

Puerto Rico forma parte del territorio aduanero de EEUU, por lo que existe libre movilidad de bienes y servicios y, como cabría esperar, el mayor volumen de intercambios comerciales de Puerto Rico se produce con EEUU, lo que analizamos posteriormente.

Dada la importancia de estos intercambios, es necesario mencionar la Ley Jones de 1917, sobre cabotaje, que establece que todo tráfico marítimo entre la isla y los puertos estadounidenses debe realizarse en buques de la marina mercante de EEUU, fabricados en ese país y con tripulación de ciudadanía estadounidense.

Aunque existe controversia sobre los efectos de dicha ley, existen algunos análisis, incluso presentados al Senado ${ }^{1}$, que concluyen que una apertura a la competencia en el transporte marítimo entre EEUU y Puerto Rico abarataría notablemente los costes de los productos importados, puesto que solo cuatro firmas sirven regularmente en el mercado de Puerto Rico.

Tras el huracán María se derogó esta ley en Puerto Rico durante diez días, lo que permitió la entrada de diez buques extranjeros, facilitando la llegada de productos de primera necesidad desde EEUU (agua, generadores, gasolina, productos de bebé, etcétera), lo cual demostró la necesidad de revisar dicha ley, que, no obstante, incluye aspectos tan importantes como el acceso a la ciudadanía americana de los nacidos en Puerto Rico.

Comisión de Derechos Civiles, Participación Ciudadana y Economía Social, abril de 2015.

\subsection{Puerto Rico dentro de la Reserva Federal}

Como se podría esperar, el dólar es la moneda oficial de Puerto Rico y, al estar dentro de la jurisdicción de EEUU, no cuenta con una política monetaria propia, sino que esta depende de la Reserva Federal norteamericana. Puerto Rico forma parte del segundo distrito adscrito al Banco de la Reserva Federal de Nueva York², uno de los doce bancos más importantes de la Reserva Federal.

A su vez, como Estado Libre Asociado de EEUU, Puerto Rico no es reconocido como miembro del Fondo Monetario Internacional (FMI) y, por lo tanto, no es elegible para apoyo financiero ni asistencia técnica, y no ha sido incluido en los programa de ajustes estructurales existentes ${ }^{3}$. En este contexto, destacar que Puerto Rico tampoco es elegible para ser receptor de las líneas de emergencia de apoyo financiero existentes por catástrofes naturales en organismos internacionales como el Banco Mundial (BM) o el Banco Interamericano de Desarrollo (BID), como quedó patente tras los recientes huracanes.

No obstante, como aspecto positivo, resaltar que en Puerto Rico, gracias a su dependencia de las agencias reguladoras de EEUU y a sus relaciones con la banca estadounidense, el sector financiero, y en particular la banca comercial, ha alcanzado niveles de desarrollo similares a EEUU, lo que supone un gran respaldo y las garantías suficientes para atraer inversores bajo la Ley 22, que se explicará a continuación.

\footnotetext{
2 Del que dependen el estado de Nueva York, los doce condados norteños de Nueva Jersey, el condado de Fairfield en Connecticut, Puerto Rico y las Islas Vírgenes.

3 El FMI sí incluye a Puerto Rico en sus Perspectivas sobre la Economía Mundial.
} 


\subsection{Libre movilidad de personas y el mercado laboral}

La migración a EEUU ha sido un hecho fundamental en la vida de los puertorriqueños. Aunque legalmente no se trata de una migración, puesto que los puertorriqueños son ciudadanos de EEUU, a nivel cultural sí lo es.

Las características de los «emigrantes» han cambiado con el paso del tiempo; si bien inicialmente predominaron los trabajadores agrícolas o menos cualificados, hoy la mayor parte son trabajadores, entre 35 y 50 años, con un nivel medio alto de formación académica. La principal razón de la persistencia de la emigración es consecuencia de la falta de convergencia del empleo y de la diferencia salarial entre la isla y el continente.

Recientemente, tras el impacto del huracán María en septiembre de 2017, se ha producido un éxodo importante estimado en más de 200.000 personas, hecho que ha contribuido a reducir el número de residentes en la isla, el cual ha descendido de forma considerable, hasta los 3,2 millones de habitantes en la actualidad.

No obstante, la población total de puertorriqueños supera los seis millones de habitantes, por lo que en estos momentos hay prácticamente el mismo número de puertorriqueños fuera que dentro de la isla, principalmente en EEUU. Hoy en día, uno de los objetivos de la comunidad puertorriqueña residente en EEUU es tener algún efecto sobre los resultados electorales, especialmente en Florida, y así poder influenciar positivamente en las decisiones políticas que afectan a la isla.

Con respecto al mercado laboral, en Puerto Rico la tasa de participación laboral es considerablemente baja, inferior al $40 \%$, debido a la falta de empleos bien remunerados para los jóvenes con menos formación, así como por el fuerte apoyo a través de subsidios, lo que en Puerto Rico conocen como «el mantengo", es decir, el apoyo económico para la vivienda y alimentación, que en muchas ocasiones desincentiva la búsqueda activa de empleo.

\subsection{Incentivos fiscales}

Puerto Rico, al no ser un estado perteneciente a la Unión de Estados Americanos (EEUU), goza de un alto grado de autonomía fiscal y lo exime de fiscalidad federal.

En estos momentos de replanteamiento del futuro económico de la isla y tras el fin de algunos de los incentivos fiscales, que atrajeron especialmente al sector manufacturero, se está trabajando en un nuevo Código de Incentivos Contributivos que permita la atracción de nuevas inversiones.

Actualmente, en el marco impositivo de atracción de inversiones, debemos resaltar las dos leyes vigentes con mayor relevancia:

- Ley n. 20/2012 de exportación de servicios, que fundamentalmente establece incentivos contributivos para las empresas que elijan Puerto Rico como base para la exportación de servicios, con un tipo máximo del $4 \%$, además de otras exenciones a la propiedad y el reparto de los beneficios. Al ser de aplicación en la isla la legislación federal estadounidense, la prestación de servicios dirigidos al territorio continental de EEUU resulta muy atractiva, pues el coste de instalación y de la mano de obra es inferior.

- Ley n. 22/2012 para inversores: tiene el objetivo de incentivar el traslado de inversores individuales como residentes permanentes en Puerto Rico (un mínimo $\triangleright$ 
de 183 días). Se establece una exención contributiva del $100 \%$ de los ingresos de todas las fuentes. Incluye intereses y dividendos, entre otros beneficios.

En estos momentos, en Puerto Rico se está trabajando en un nuevo Código de Incentivos Contributivos que ayude tanto a reactivar el dinamismo inversor como a contrarrestar la reforma fiscal aprobada a nivel federal en enero de 2018, la cual podría afectar negativamente a Puerto Rico. Muchas de las empresas estadounidenses establecidas en la isla lo están como Corporaciones Extranjeras Controladas (Controlled Foreign Corporation, o CFC). La reforma fiscal obliga a tributar a estas corporaciones un $14 \%$ de las ganancias generadas fuera del país norteamericano, además de gravar en un $20 \%$ las compras que las empresas hagan de sus afiliadas fuera de territorio nacional, incluyendo Puerto Rico.

La dificultad principal de desarrollar un Código de Incentivos Contributivos atractivo es la situación financiera actual. Cualquier reforma debe ser avalada por la Junta de Control Fiscal, que solicita al Gobierno la necesidad de mantener o incrementar el nivel de ingresos reduciendo el nivel de gasto, con el objetivo de poder hacer frente al pago de la deuda.

\subsection{El problema de la deuda}

La deuda pública de Puerto Rico está compuesta principalmente por las deudas de las empresas públicas ( $70 \%$ del total), los municipios y el Gobierno central. El origen del fuerte aumento de la deuda se explica por el colapso del modelo económico de la isla a finales de la década de 1990, lo que generó una importante reducción en la recaudación pública y, a su vez, una fuerte emisión de deuda por parte de las corporaciones para compensar la disminución de los ingresos.

Otro factor responsable de la deuda es el proceso de la desindustrialización, que llevó a perder importantes clientes industriales, reduciéndose la demanda de energía y de agua y, por tanto, de ingresos, y afectando directamente a dos de las más grandes corporaciones del Gobierno, la Autoridad de Energía Eléctrica (AEE) y la Autoridad de Acueductos y Alcantarillados (AAA), que no llevaron a cabo una restructuración de los gastos.

El déficit estructural que arrastraban las cuentas públicas obligó al Gobierno de Puerto Rico a tomar importantes medidas de ajuste del gasto; sin embargo, a pesar de estos esfuerzos presupuestarios, en febrero de 2014 Standard \& Poor's rebajó la calificación de la deuda pública de Puerto Rico a grado especulativo, un nivel por debajo del grado de inversión.

El 3 de agosto de 2015, por primera vez, Puerto Rico no hizo frente al vencimiento de su deuda pública. Esto llevó a que las Cámaras Legislativas de Puerto Rico establecieran una Ley de Moratoria que les permitiera poder dejar de pagar la deuda y evitar las demandas de los acreedores. En este contexto, destacar que la deuda total de Puerto Rico supera los 73.000 millones de dólares y las obligaciones futuras contraídas por los planes de pensiones de los empleados públicos, otros 49.000 millones de dólares.

Ante esta situación, la Administración de Puerto Rico solicitó ayuda a EEUU y el Tesoro Federal inició el proceso para aprobar una legislación específica que pudiera resolver el problema fiscal de Puerto Rico. En 2016, tanto republicanos como demócratas aprobaron la ley PROMESA (Puerto Rico Oversight, Management and Economic Stability). Los dos $\triangleright$ 
puntos más importantes de esta legislación son el establecimiento de una Junta de Supervisión Fiscal (JSF), responsable de realizar una consolidación fiscal a cinco años vista, y la posibilidad de que Puerto Rico reestructure su deuda, bien voluntariamente o bien bajo el amparo judicial. Finalmente, en mayo de 2017, el Gobernador de Puerto Rico solicitó acogerse al proceso de quiebra, con la finalidad de que sean los tribunales los que fijen los términos del pago de la deuda.

El asunto de la deuda en Puerto Rico es muy complejo, ya que hay 18 distintos emisores de deuda pública y cada tipo de deuda cuenta con unas garantías diferentes. Dentro de los acreedores también hay una gran diversidad: fondos de inversión, bancos..., incluyéndose también cooperativas de crédito locales, por lo que estos impagos podrían tener un impacto directo en las cuentas de algunas entidades de crédito de la isla.

En estos momentos continúan avanzando las negociaciones con los diferentes grupos de bonistas, habiéndose alcanzado tres acuerdos de reestructuración parcial de la deuda con la Corporación del Fondo de Interés Apremiante (COFINA), con la Autoridad de Energía Eléctrica (AEE) y con el Banco Gubernamental de Fomento. Según el plan fiscal certificado por la Junta de Supervisión fiscal, el sobrante primario, disponible para el pago de la deuda, ascendería a unos 1.200 millones de dólares anuales para los próximos cinco años.

En este sentido, es de especial interés el reciente artículo de Joseph Stiglitz, Pablo Gluzzmannn y Martín Guzmán (2018) sobre el análisis y la necesidad de aliviar el volumen de deuda de Puerto Rico ${ }^{4}$. En el mismo destacan

4 «An analysis of Puerto Rico's debt Relief needs to restore debt sustainability». Working Paper 252256. National Bureau of Economic Research. la fragilidad del modelo económico de Puerto Rico, basado en «una industrialización centrada en los incentivos fiscales» y en la imposibilidad de alcanzar niveles de deuda sostenibles sin una cancelación en torno al $60 \%$ del total de la deuda que asciende a 72.000 millones. Además, destaca que, dado el nivel de incertidumbre de la implementación del Plan Fiscal y de la evolución de la economía de la isla, una posible solución en la reestructuración de la deuda podría ser incluir bonos alineados a la evolución del PIB, en la que se ajustarían los pagos de la deuda a la capacidad real de repago y, por definición, tanto los deudores como los acreedores se beneficiarían de una recuperación económica.

En definitiva, el objetivo es reestructurar el total de la deuda con un plan creíble, el cual exige numerosas reformas estructurales; incluyendo la reducción del tamaño de la Administración, el cumplimiento del plan fiscal establecido por la Junta de Supervisión Fiscal y, como indica el artículo recientemente mencionado, contemplar la inclusión de un fuerte alivio o condonación de la deuda, para que esta sea sostenible, lo que tendrá como contrapartida una merma en cuanto a la credibilidad o coste de los futuros bonos emitidos por la Administración de Puerto Rico.

\subsection{Transferencias recibidas}

En esta situación de quiebra económica juegan un papel aún más importante las aportaciones del Gobierno federal a la isla, que históricamente han representado el mayor flujo de recursos hacia Puerto Rico. Además de las aportaciones a las agencias federales que operan en Puerto Rico, donde destacan los gastos a agencias militares, así como al Departamento de Justicia o Tesoro, los desembolsos del $\triangleright$ 
Gobierno federal incluyen las transferencias a los residentes en Puerto Rico, así como las aportaciones al Gobierno central y a los municipios.

Como podemos observar en la Tabla 1, en los últimos cinco años, las transferencias federales ascienden a más de 18.000 millones de dólares anuales, mientras que los pagos no superan los 4.000 millones de dólares anuales. Esto resulta una aportación positiva anual para la economía de Puerto Rico por un valor de 14.000 millones de dólares anuales.

Como se puede observar, dentro de los ingresos la gran parte de las transferencias provienen de los beneficios del Seguro Social o de los beneficios del MediCare. También resaltar la importancia del Programa de Alimentos Nutricional
(PAN), que recibe transferencias por valor de casi 2.000 millones de dólares anuales, y del cual se benefician las rentas más bajas.

Las transferencias federales son objeto de numerosos debates. Por un lado, se defiende que el modelo actual de Estado Libre Asociado ha creado un estancamiento económico basado en una dependencia excesiva de las políticas y transferencias del Congreso de EEUU, sin que Puerto Rico pueda tener acceso a algunas decisiones políticas relevantes, como la política comercial, la política monetaria o gozar de representación en los principales organismos económicos internacionales.

Otros argumentan que gracias a esta «dependencia» y a las transferencias federales $\triangleright$

TABLA 1

TRANSFERENCIAS ENTRE PUERTO RICO Y EL GOBIERNO FEDERAL, GOBIERNOS ESTATALESY OTROS NO RESIDENTES: AÑOS FISCALES

\begin{tabular}{|c|c|c|c|c|c|}
\hline & 2012 & 2013 & 2014 & 2015 & 2016 \\
\hline Ingresos & 17.463 & 18.106 & 17.981 & 17.943 & 18.152 \\
\hline Gobierno federal, total & 16.482 & 16.967 & 16.953 & 17.017 & 17.222 \\
\hline Transferencias a individuos & 16.238 & 16.751 & 16.739 & 16.863 & 16.983 \\
\hline Beneficios a veteranos & 899 & 807 & 869 & 1.416 & 1.230 \\
\hline Beneficios de MediCare & 3.188 & 4.148 & 4.481 & 4.467 & 4.511 \\
\hline Beneficios de Seguro Social & 7.549 & 7.929 & 7.354 & 7.718 & 7.820 \\
\hline Becas & 1.012 & 895 & 909 & 789 & 780 \\
\hline Pensiones del Sistema Federal de Retiro & 314 & 134 & 138 & 141 & 143 \\
\hline Ayuda para la vivienda & 587 & 630 & 791 & 216 & 208 \\
\hline Asistencia nutricional & 1.897 & 1.868 & 1.869 & 1.846 & 1.908 \\
\hline Otros & 0 & 0 & 0 & 0 & 0 \\
\hline Subsidios a industrias & 244 & 216 & 214 & 228 & 239 \\
\hline Gobiernos estatales de EEUU & 20 & 30 & 30 & 34 & 34 \\
\hline Otros no residentes & 961 & 1.109 & 998 & 892 & 896 \\
\hline Pagos & 3.752 & 3.745 & 3.870 & 3.988 & 3.967 \\
\hline Gobierno federal, total & 3.644 & 3.653 & 3.762 & 3.848 & 3.837 \\
\hline Transferencias a individuos & 1.887 & 1.924 & 1.936 & 1.982 & 1.946 \\
\hline Transferencias a industrias & 105 & 104 & 127 & 133 & 137 \\
\hline Aportación al seguro por desempleo & 212 & 214 & 217 & 248 & 283 \\
\hline Aportaciones de los patronos a sistemas de SS & 1.440 & 1.411 & 1.482 & 1.485 & 1.471 \\
\hline Gobiernos estatales de EEUU & 4 & 3 & 3 & 2 & 3 \\
\hline Otros no residentes & 105 & 89 & 105 & 139 & 128 \\
\hline Balance neto & 13.711 & 14.361 & 14.111 & 13.955 & 14.185 \\
\hline
\end{tabular}


la isla ostenta un nivel de desarrollo y un nivel de renta per cápita y de cobertura de las necesidades básicas muy superior a sus países vecinos de Centroamérica y Caribe. En estos momentos, el PIB per cápita se encuentra en torno a los 28.000 dólares anuales, sin olvidar que el índice de Gini asciende a 0,54, siendo Puerto Rico uno de los países donde más ha aumentado la desigualdad en los últimos años, según datos del Centro de Información Censal de la Universidad de Cayey de Puerto Rico, que utiliza datos del Banco Mundial del $2017^{5}$.

Entre las fuentes de ingresos también hay que mencionar las remesas individuales que se reciben desde EEUU, que suponen otro apoyo importante a la economía familiar. En este marco, podemos destacar que el $60 \%$ de los puertorriqueños reside fuera de la isla, lo que explica la importancia de las remesas que llegan principalmente desde EEUU.

\section{Intercambios comerciales de Puerto Rico}

\subsection{Puerto Rico-EEUU}

Puerto Rico forma parte del territorio aduanero de EEUU, por lo que aunque, para simplificar, hablamos de exportaciones e importaciones, deberíamos hablar de intercambios comerciales con el que es, sin duda, su principal socio comercial.

Según datos de la Junta de Planificación de 2017, el volumen total de las exportaciones de Puerto Rico a EEUU asciende a $51.280 \mathrm{mi}-$ llones de dólares, mientras que las importaciones superan los 23.160 millones de dólares, lo

5 http://www.upr.edu/iii-cayey/mdocs-posts/notas-del-centrode-informacion-censal-cic-29-desigualdad-social-en-puerto-rico-vs-elmundo/ que representa el $83,42 \%$ y el $56 \%$ de las exportaciones e importaciones totales de Puerto Rico.

Por un lado, el saldo positivo de la balanza comercial se explica por el valor de los productos exportados, principalmente derivados del sector farmacéutico. Por otro lado, no sorprende que la mayor parte de los intercambios se produzcan con EEUU, tanto por la presencia de entidades americanas en la isla como por la libre movilidad de bienes y servicios entre ambas partes.

Dada esta dependencia comercial, uno de los puntos más importantes es analizar el impacto directo de la política arancelaria actual de EEUU con el resto del mundo. El pasado mes de marzo, el presidente de EEUU adoptó medidas de salvaguardia por motivos de seguridad nacional, bajo la sección 232 de la Trade Expansion Act, que implican la imposición de una tasa adicional del $10 \%$ de todas las importaciones de aluminio y del $25 \%$ para el acero.

Estas subidas tendrán un impacto directo sobre los precios de importación de las materias primas, componentes industriales (baterías y placas solares) y materiales de construcción, tan necesarios en este momento para la reconstrucción de la isla.

\subsection{Puerto Rico-resto del mundo}

A la hora de analizar los bienes y servicios exportados por Puerto Rico al resto del mundo hay que destacar los bienes producidos por la industria farmacéutica, ya que estos suponen un $70,19 \%$ del total de las exportaciones puertorriqueñas, así como otras industrias de alta tecnología. Este alto nivel de exportación ha tenido efectos muy positivos en la economía, generando un importante volumen de ingresos y de empleos. Le siguen en importancia los $\triangleright$ 


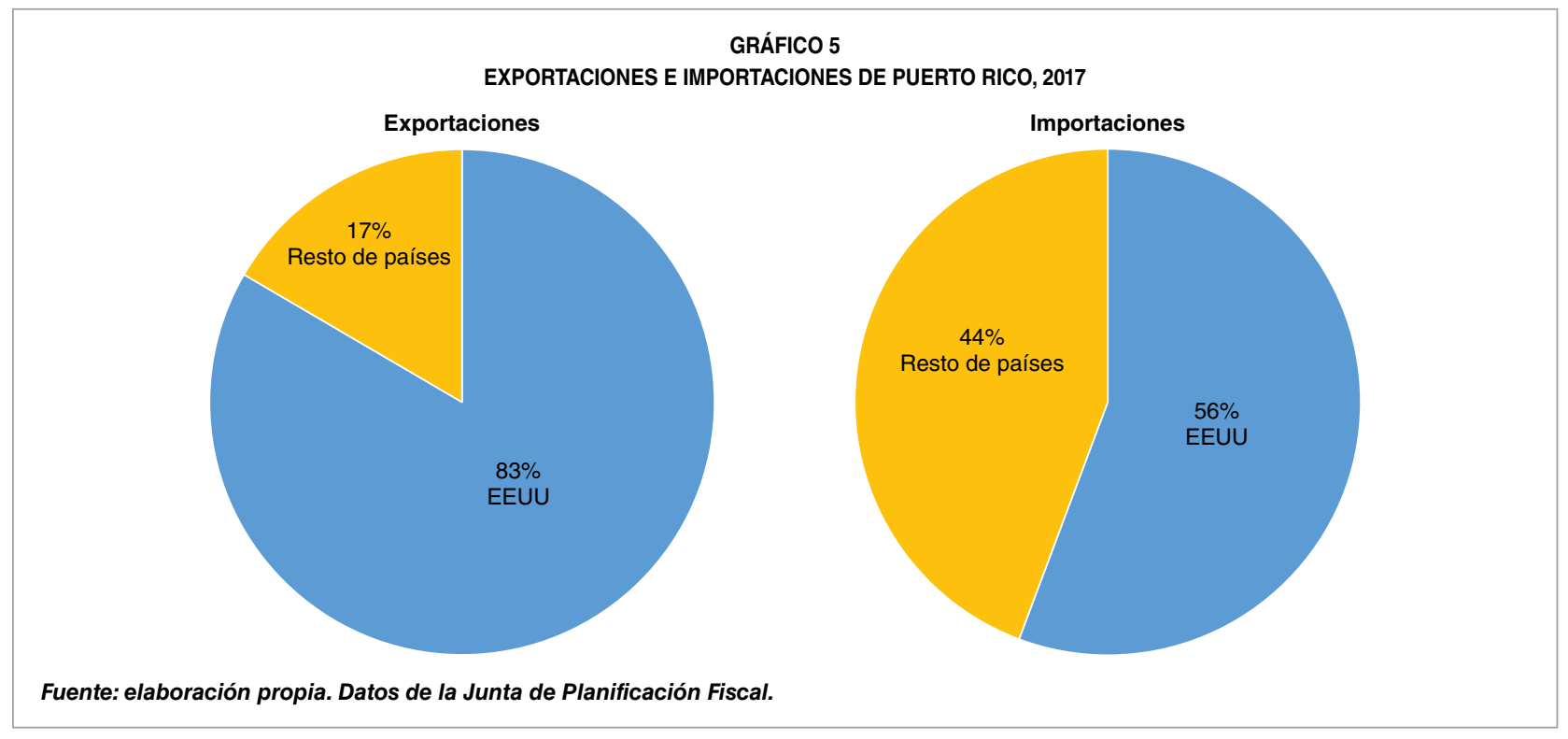

instrumentos y aparatos ópticos y médicos quirúrgicos $(11,20 \%) \mathrm{y}$, en tercer lugar, los productos químicos $(7,44 \%)$. Por tanto, todas las categorías están relacionadas directa o indirectamente con la industria farmacéutica. Además, las exportaciones en esta categoría siguen creciendo, habiendo aumentado en 2017 un $0,12 \%$ con respecto al año 2016, representando un total de $51.671,5$ millones de dólares.

Una de las consecuencias actuales del desarrollo de la manufactura desde los años 1980 es que Puerto Rico es una de las economías más abiertas del mundo. En el año 2017 el comercio total de bienes y servicios sumó 167.103,4 millones de dólares, lo que supone una tasa de apertura del $160 \%$. No obstante, a pesar de que Puerto Rico exporta una gran porción de su producción interna, la industria de capital local tiene una participación muy limitada en dichas exportaciones.

La mayor parte de las inversiones en estos sectores se encuentra en manos de capital privado extranjero, lo cual, como mencionamos previamente, explica las fuertes diferencias entre el PIB y el PNB de la isla. La repatriación de beneficios que realizan las compañías estadounidenses establecidas en la isla, en los sectores farmacéuticos, biotecnológico y de dispositivos médicos, hace que la partida de gastos de capital se vea afectada, obteniendo un saldo negativo superior a 35.000 millones de dólares en 2017.

Con respecto a las importaciones, las dos principales categorías son los productos farmacéuticos $(27,39 \%)$ y los productos químicos $(16,89 \%)$, siendo la justificación de ello la necesidad de importar bienes intermedios necesarios para la producción farmacéutica.

A nivel de importaciones, Irlanda destaca como el principal socio comercial de la isla (22,8\% del total en 2017). Esto es debido a que su industria farmacéutica suple de insumos a empresas relacionadas en Puerto Rico, ascendiendo el valor de las importaciones a 4.200 millones de dólares.

\subsection{Puerto Rico-España}

Teniendo en cuenta la gran diferencia de tamaño y población entre España y Puerto $\triangleright$ 


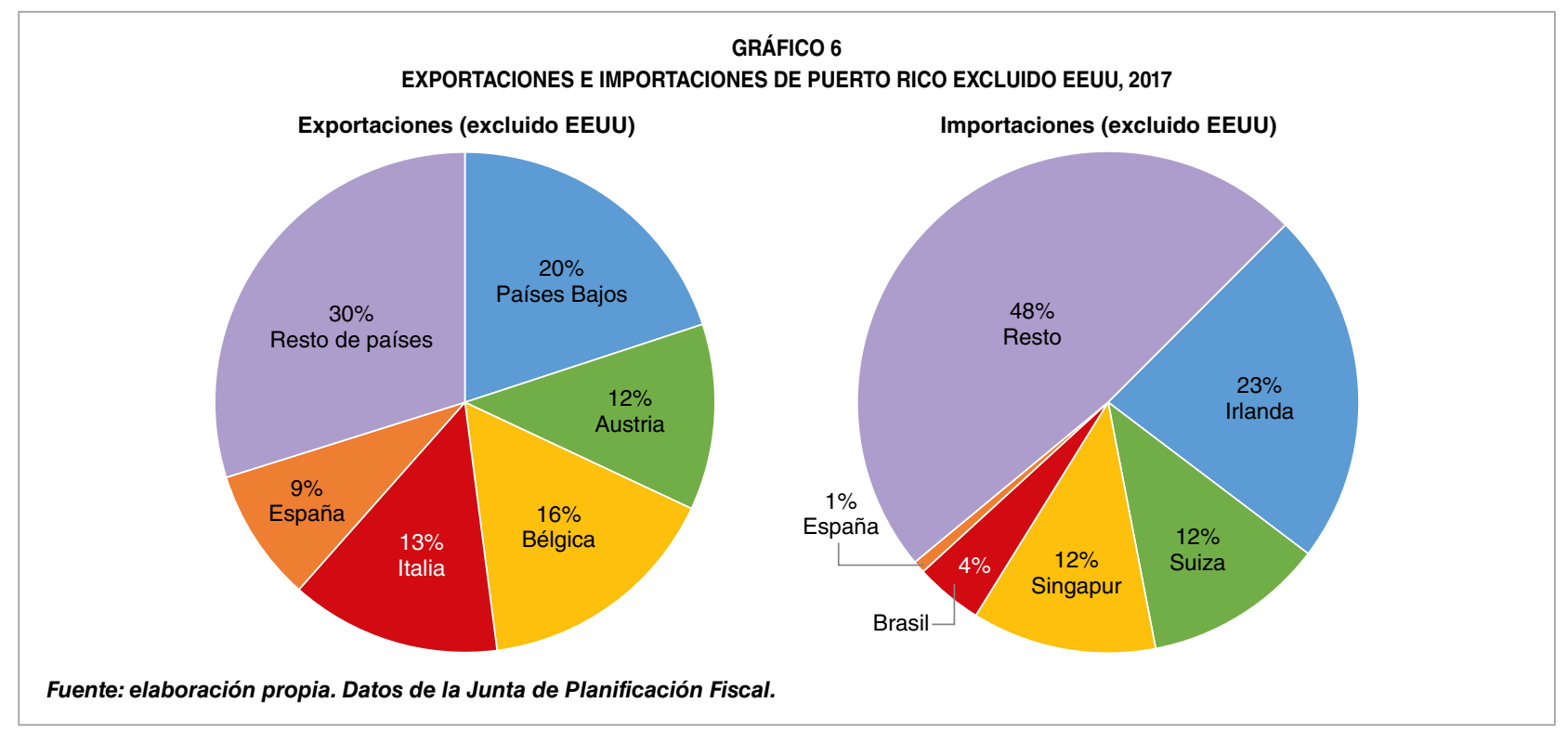

Rico, resulta curioso observar que el valor de las exportaciones puertorriqueñas a España es seis veces superior al de importaciones $(877,35$ millones de dólares frente a 146,2 millones de dólares en 2017). La justificación procede, una vez más, de la industria manufacturera, ya que la práctica totalidad de las exportaciones son productos farmacéuticos (98,3\%). Queda constancia, por tanto, de que Puerto Rico es un

TABLA 2

INTERCAMBIOS COMERCIALES CON ESPAÑA, 2017

(En dólares y porcentaje sobre el total)

\begin{tabular}{|l|r|r|}
\hline \multicolumn{3}{|c|}{ Exportaciones } \\
\hline Productos farmacéuticos & 862.478 .487 & $98,30 \%$ \\
Máquinas, aparatos y mat. eléctrico & 6.430 .684 & $0,73 \%$ \\
Productos de las industrias químicas & 3.130 .842 & $0,36 \%$ \\
Productos químicos orgánicos & 1.038 .720 & $0,12 \%$ \\
Resto & 4.275 .338 & $0,49 \%$ \\
\hline Total & 877.354 .071 & \\
\hline \multicolumn{2}{|c|}{ Importaciones } \\
\hline Combustibles y aceites minerales & 16.597 .658 & $11,35 \%$ \\
Productos químicos orgánicos & 15.335 .291 & $10,49 \%$ \\
Bebidas, beb. alcohólicas y vinagre & 15.372 .093 & $10,51 \%$ \\
Grasas y aceites animales/vegetales & 12.860 .636 & $8,79 \%$ \\
\hline Resto & 86.079 .233 & $58,86 \%$ \\
\hline Total & 146.244 .911 & \\
\hline Fuente: elaboración propia. Datos de la Junta de Planificación \\
Fiscal.
\end{tabular}

centro mundial dentro de la industria farmacéutica, con gran número de multinacionales del sector, la mayoría estadounidenses.

Por otro lado, al hablar de las importaciones de Puerto Rico desde España podemos, por un lado, hablar de bienes tradicionales de consumo asociados con España, como el vino, aceite de oliva, cerámica de construcción o conservas, que tiene una evolución bastante estable; y, por el otro lado, los combustibles minerales y productos químicos orgánicos, cuyo volumen sufre importantes oscilaciones en el tiempo y que llegan a explicar hasta el $75 \%$ de las importaciones totales de España. La significativa reducción de las importaciones desde España, en el periodo 2011-2017, se debe principalmente a una caída relevante en la partida de hidrocarburos.

\section{Retos y oportunidades}

Como aspectos más relevantes para el futuro de la economía de Puerto Rico, la presencia destacada de la industria farmacéutica y otras de alta tecnología ha tenido efectos muy $\triangleright$ 
positivos más allá de la generación de ingresos y empleos. Puerto Rico, gracias a contar con una de las concentraciones mayores de producción farmacéutica, tiene rango de centro de producción de alta tecnología, lo cual debería facilitar la promoción de nuevas industrias que aceleren la inserción de la actividad local en las cadenas globales de producción.

Puerto Rico posee grandes atractivos para ser considerado como la vía natural de entrada a EEUU para empresas extranjeras, especialmente españolas: el país cuenta con proveedores de servicios profesionales e ingeniería que cuentan con conocimiento y experiencia en la implementación de la normativa federal, pero a su vez se trata de un mercado más pequeño, con mano de obra cualificada, bilingüe (español e inglés) y costes laborales menores (se aplica el salario mínimo federal).

En estos momentos, teniendo en cuenta su situación financiera y ante la falta de recursos públicos para afrontar mejoras en los servicios públicos e infraestructuras, se está impulsando el modelo de las alianzas público-privadas (APP), teniendo ya ejemplos exitosos como la cesión de la gerencia del Aeropuerto Internacional de San Juan o la concesión de varias autopistas, en este último caso a una empresa española.

A lo largo de los años 2017 y 2018 se ha publicado un inventario de propuestas de proyectos prioritarios para ser desarrollados como alianzas público-privadas, consistente en 21 proyectos en distintos sectores: energía, transporte, puertos y aeropuertos, y estacionamientos, algunos ya lanzados y en los que se cuenta con participación de empresas españolas.

Se espera que 2019 sea un año clave para la transformación del sistema energético en Puerto Rico. Recientemente, se ha aprobado el marco regulatorio que establece la privatización de lo que hasta ahora estaba en manos de un único operador, la Autoridad de Energía Eléctrica.

\subsection{Oportunidades en el marco de la reconstrucción}

El paso del huracán María agravó la ya de por sí complicada situación del Estado Libre Asociado de Puerto Rico. Sin embargo, como a veces ocurre, los retos se convierten en oportunidades, y la necesidad de reconstrucción de la isla supone una de las mayores oportunidades para la inversión extranjera en estos momentos.

El gobernador de Puerto Rico estimó los daños en las infraestructuras de la isla en 94.400 millones de dólares y presentó ante el comité de Recursos Naturales del Congreso de EEUU un plan de reconstrucción por ese importe, denominado Build Back Puerto Rico.

Puerto Rico, como Estado Libre Asociado de EEUU, no recibe fondos de asistencia de ninguna institución financiera multilateral, ni tampoco es elegible para ser receptor de fondos de cooperación al desarrollo. Todo el apoyo financiero, tras una catástrofe natural, depende de la entidad de manejo de emergencias de EEUU, conocida como FEMA (Federal Emergency Management Agency). Las estimaciones más realistas calculan que los fondos comprometidos para la reconstrucción de la isla superarán los 40.000 millones de dólares. Se espera que estos fondos permitan modernizar gran parte de sus infraestructuras y reactiven la economía local a través de la transformación del sector de la energía, la construcción de viviendas y carreteras o la dinamización del turismo, entre otros.

Los daños en las infraestructuras de Puerto Rico incluyen deterioros graves a unas 472.000 unidades de vivienda, así como a tres cuartas partes de todas las subestaciones eléctricas $\square$ 
y la casi totalidad de las plantas de depuración de agua. También se ha previsto la necesidad de intervenciones en 175 hospitales y clínicas de salud, además de importantes reparaciones en los sistemas de carreteras y puentes, así como en los aeropuertos. En este marco, se esperan importantes oportunidades de negocio derivadas de las licitaciones que surgirán para estos proyectos y que cuenten con el apoyo de los fondos de FEMA.

\subsection{Jornadas técnicas multisectoriales Puerto Rico-España}

En este marco, los pasados 16 y 17 de octubre, con el apoyo del ICEX, tuvimos la ocasión de celebrar en Puerto Rico las Jornadas Multisectoriales para la Reconstrucción: Puerto Rico-España. Contamos con la participación de 14 empresas españolas procedentes de los sectores de energía, infraestructuras y construcción principalmente, y con 20 empresas locales interesadas en participar en el encuentro B2B de la tarde.

El primer día se celebró el encuentro con las autoridades del Gobierno de Puerto Rico, que tuvo lugar en formato de mesas sectoriales, y en el que las empresas tuvieron ocasión de discutir las futuras oportunidades con:

- El Departamento de Vivienda.

- La Autoridad de Energía Eléctrica (AEE).

- La Autoridad de Puertos.

- El Departamento de Transporte y Obras Públicas (DTOP).

- La Autoridad para el Financiamiento de la Infraestructura (AFI).

- La Autoridad de Acueductos y Alcantarillados (AAA).

- La Autoridad de las Alianzas Público Privadas (P3).
- La Oficina Central de Recuperación Reconstrucción (COR3).

El segundo día de la jornada se dedicó a la realización de visitas técnicas de proyectos locales de interés relacionados con infraestructura, energía y construcción.

Se espera que, tras las jornadas, las empresas se animen a participar en los procesos de licitación que están surgiendo con el apoyo financiero de los fondos federales.

\section{Conclusión}

Puerto Rico, como Estado Libre Asociado de EEUU, no recibe fondos de asistencia de ninguna institución financiera multilateral, ni es elegible para ser receptor de fondos de cooperación al desarrollo de otros países. Todo el apoyo financiero tras una catástrofe natural depende de la entidad de manejo de emergencias de EEUU, FEMA (Federal Emergency Management Agency). Las estimaciones más realistas prevén que los fondos comprometidos para la reconstrucción de la isla superarán los 60.000 millones de dólares. Estos fondos permitirán modernizar gran parte de sus infraestructuras y reactivar la economía local a través de la transformación del sector de la energía, la construcción de viviendas y carreteras o la dinamización del turismo, entre otros.

En este contexto, Puerto Rico se encuentra en un momento crucial para determinar su futuro económico y social. Las perspectivas ante la recepción de numerosos fondos federales son positivas para los próximos años y servirán para mitigar el efecto de las reformas dolorosas y la dosis de austeridad que su situación financiera exige y que implementa por mandato $D$ 
la Junta de Supervisión Fiscal, como parte del proceso de quiebra.

Parece que existe consenso entre los economistas en la necesidad de implementar las reformas estructurales mientras se lleva a cabo la reconstrucción física de la isla. El Gobierno y la sociedad en su conjunto no pueden ignorar los desafíos más importantes: la vuelta a los mercados de capitales, el éxodo de la población y la reducción de la desigualdad.

\section{Bibliografía}

[1] Alameda, J.; Rivera, I. y Pérez, A. (1989). La sensibilidad de la economía de Puerto Rico ante los ciclos económicos de Estados Unidos. Revista Interamericana (primavera-verano), 29(1-2), 109-134.

[2] Caraballo-Cueto, J. (2015). Some Determinants of the Puerto Rican Migration to the US in 1950-2014. CIDE Digital, 6(1), 22-30.

[3] CEPAL (2004). Globalización y Desarrollo: Desafíos de Puerto Rico frente al siglo xxı.

[4] Cremades y Calvo Sotelo (2018). Informes económicos mensuales. Puerto Rico.

[5] Davis, S. J. y Rivera-Batiz, L. A. (2006). The Climate for Business Development and
Employment Growth. In: Collins, S.; Bosworth, B. y Soto Class, M. (eds.). The Economy of Puerto Rico: Restoring Growth. Washington, DC: Center for a New Economy, Brookings Institution Press.

[6] Dietz, J. L. (1986). Economic History of Puerto Rico: Institutional Change and Capitalist Development. Princeton: Princeton University Press.

[7] Gluzmann, P. A.; Guzmán, M. M. y Stiglitz, J. E. (2018). An Analysis of Puerto Rico's Debt Relief Needs to Restore Debt Sustainability (No. w25256). National Bureau of Economic Research.

[8] Gobierno de Puerto Rico (2016). Transferencias federales en Puerto Rico. (Datos de la Autoridad de Asesoría Financiera y Agencia Fiscal de Puerto Rico).

[9] Instituto de Estadísticas de Puerto Rico (2018). Primer Informe sobre Desarrollo Humano de Puerto Rico 2016.

[10] Junta de Planificación de Puerto Rico (2018). Informe económico del Gobernador.

[11] Peck, R. B. (2009). Política fiscal federal en Puerto Rico: modelo correlacional de consecuencias electorales. Revista de Administración Pública, 41(1), 167-188.

[12] Villamil, J. J. (1976). El modelo puertorriqueño: Los límites del crecimiento dependiente. Revista Puertorriqueña de Investigaciones Sociales, 1(1), 3-14. 